\title{
An Interface and Communication Technique between Circuit Blocks in System LSI
}

\author{
Masafumi Hayakawa Member (Tokyo Denki University) \\ Tsugio Nakamura Member (Tokyo Denki University) \\ Narito Fuyutsume Member (Tokyo Denki University) \\ Hiroshi Kasahara Member (Tokyo Denki University) \\ Teruo Tanaka Member (Tokyo Denki University)
}

Keywords : system LSI, system on chip, intellectual property core, modularization, network on chip

As for the next generation of ultra large-scale integrated circuit in System-LSI/SoC, how to standardize the communication method and interface between diversified cores becomes one of the important problems, and various study reports have been done.

We propose a new method to solve the problem, where the communication between the cores is limited only to using message + parameters format. As the communication mechanism between IP cores and a common bus, we introduced the architecture, ACU, common to every core with various $\mathrm{I} / \mathrm{O}$ functions, and it can be realized with less than $5 \mathrm{k}$ gates scale.

As the paradigm of Globally-Asynchronous LocallySynchronous(GALS) system is attracting attention, this method is believed to be a good suggestion as a communication mechanism between local IP cores. In this case, it accompanies the problem of how to build up bus arbitration system. The Access Control Unit(ACU), we proposed, is an extremely simple architecture that does not need the bus arbitration system.

The exclusive use of the bus is controlled by the token method. In Fig. 1, the communication protocol from IP core-2 to IP core-N is as follows.

If ACU-2 gets a token in the state that a "request to send" signal comes out of core-2 to ACU-2, ACU-2 returns a "clear to send" signal to IP core-2, and then IP core-2 sends data to ACU- 2. ACU-2 translates the destination address(IP core-N) into the address of ACU-N and sends the data adding a source address of ACU-2 on the bus. When each ACU detects a start signal of a message, they all receive the message and compare the destination address with one's own address, and only one ACU corresponding to the address(in this case, it is IP core-N) receives the attached

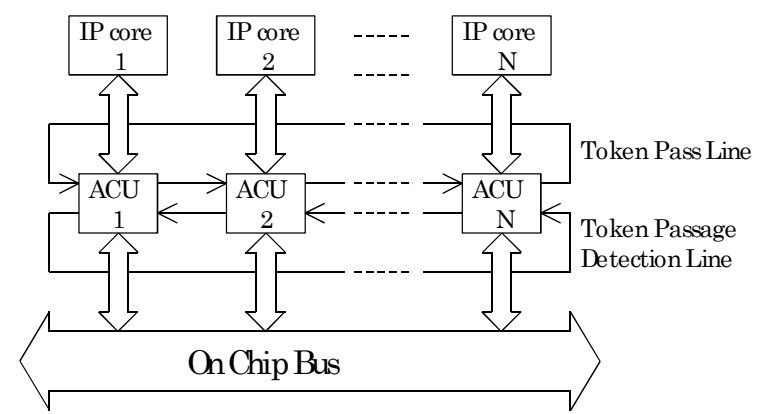

Fig. 1. Connection outline of the IP cores

parameters and output a "request to send" signal to IP core connected to the ACU. After receiving the "clear to send" signal from IP core-N, ACU-N stores the source address(in this case, it is IP core-2) temporarily and sends out the attached data to core-N.

The response data processed by IP core-N are sent back to ACU-N, and ACU-N sends out the data on the bus, after translating the source address that has been stored in ACU-N to the destination address. As well as the above mentioned transmission protocol from the ACU-2, each ACU compare the destination address with one's address, and only ACU-2 with the corresponding address receives following parameters(data processed by IP core-N) and completes sending the answer data to IP core-2. After the transmission, the token is passed to following ACU-3 using "token pass line". As a result, IP core 3 gets the right of using the bus.

The token arrived at core- $\mathrm{N}$ is passed to core-1. In this way, the token is circulated on the "token pass line". 


\section{システム LSI 回路ブロックのインタフェースと通信方式}

$\begin{array}{llll}\text { 正員 早川 雅文* } & \text { 正員 中村 次男* } \\ \text { 正員 冬爪 成人* } & \text { 正員 笠原 宏* } \\ \text { 正員 田中 照夫** } & & & \end{array}$

\section{An Interface and Communication Technique between Circuit Blocks in System LSI}

Masafumi Hayakawa*, Member, Tsugio Nakamura*, Member, Narito Fuyutsume*, Member, Hiroshi Kasahara*, Member, Teruo Tanaka**, Member

In large-scale System-LSI/SoC, how to standardize the communication method between diversified cores becomes one of the important problems, and various study reports have been done.

We propose a new method to solve the problem, where the communication between the cores is limited only to using message + parameters format. As the communication mechanism between IP cores and a common bus, we introduced the architecture, $\mathrm{ACU}$, common to every core with various I/O functions, and it can be realized with less than $5 \mathrm{k}$ gates scale.

As the paradigm of Globally-Asynchronous Locally-Synchronous(GALS) system is attracting attention, this method is believed to be a good suggestion as a communication mechanism between local IP cores.

キーワード : システム LSI, システム・オン・チップ, IP コア，モジュール化，ネットワーク・オン・チップ

Keywords : system LSI, system on chip, intellectual property core, modularization, network on chip

\section{1. まえがき}

超高集積化時代を向かえ, システム LSI, システム・オン・ チップ（SoC）およびシステム・イン・パッケージ（SIP） においては, 10 年以内に, 数十から数百という回路ブロッ ク（Intellectual Property Core : IP コア）が一つのチップ上に 集積可能となると予測されている(1)(2)。この規模の集積化に おいては電源電圧と消費電力, IP コア間の同期化とインタ フェースの標準化および通信方式など課題が山積する。ま た，数十から数百の各 IP コアがひとつのチップ上に集積さ れるとなると, 従来のバス形ネットワークでは通信効率と 消費電力の点で障害となることから，各 IP コア間を相互に 接続するネットワークオンチップ（NoC）の構想が報告され ている(1) (6)。また，このような大規模なチップに載せる全 回路ブロックを一つの機関で設計することは設計に要する 時間やコストなどから困難である。これには IP コアの再利

\footnotetext{
* 東京電機大学情報環境学部

T270-1382 千葉県印西市武西学園台 2-1200

Department of Information Environment Engineering School of

Information Environment, Tokyo Denki University.

Muzai Gakuendai 2-1200, Inzai Chiba 270-1382

** 東京電機大学工学部

广101-8457 東京都千代田区神田錦町 2-2

Department of Electrical Engineering School of Engineering, Tokyo Denki University.

Nishiki-chou 2-2, Kanda Chiyoda-ku Tokyo 101-8457
}

用とその流通形態が必要な手段となってくる。しかし, 開 発元の異なる IP コアの再利用にはインタフェースの標準化 が不可欠であるが，各社それぞれ独自の技術を持って競合 している現状を考慮すれば，その標準化は大変な問題であ る。この問題に対して多くの研究報告がなされており，そ の中で 3 つ例を挙げる。1つは, 各ノードに接続された IP コアはルータを介してパケット方式で通信 ${ }^{(1)}$, また, トーラ ス網において仮想チャネルなしでデッドロックフリーを保 証するルーティング手法 ${ }^{(3)}$, 次に, 各 IP コア間の同期化に関 しては，「全体的に非同期式/局所的に同期式 (GALS)」(4) (6), そして, データを 1 クロックサイクルで転送可能な大きさ に分割し，パケット方式を用いずルーティング情報は別の 配線で並走させる ${ }^{(7)}$

筆者らは, 2 つの例を注目しており, IP コア間で送受信 されるメッセージとパラメータという非常に簡素なフォー マットのメッセージ通信を行うことによって, インタフェ 一スの標準化を容易にする研究を行ってきた。今回, IP コ アとデータバスの間に通信の制御を行う機構（Access Control Unit: ACU）を配置（各 IP コアにそれぞれの ACU） することにより IP コアはその ACU とのメッセージ通信に よって目的とする IP コアと通信を行う方法を提案する ${ }^{(8)(9)}$ 。 将来の NoC においても部分的には同期式を採用すべきであ り, バス形ネットワークの問題を前述したが, 通信速度や 
効率といった機能的に見て, 特に通信頻度が多いコア間は 非同期式通信とするよりも同期通信のバス形で構成したほ うが都合のよい部分もある。この場合, バスの調停機構が 大きな課題となるが，この ACU 間のバス制御を，コンピュ 一タネットワークで用いられているトークン方式とするこ とにより, バス調停を必要としない単純な構成で実現できる。

提案する方式は単純な一系統の並列バスで，インタフェ ースプロトコルはメッセージとパラメータによる通信に限 定したことにある。そのためインタフェースの ACU は特定 の IP コアに依存しない全く同一のアーキテクチャで，イン タフェースの標準化が容易であり，また小規模で実現でき る点を特徴とするものである。

提案する通信方式を，剩余演算や多項式演算など複雑な 制御を必要とする楕円曲線暗号アクセラレータに適用し, 動作確認も行った。

以下に，各種 IP コア間の標準化を容易にするインタフェ ースおよびその通信制御機構（ACU）の概要を述べ, FPGA での実験データを報告する。

\section{IP コア間のインタフェース}

開発元の異なる多種多様な IP コアの再利用にはインタフ ェースの標準化が不可欠である。そこで，メッセージ（そ の IP コアの機能）とパラメータ（その IP コアに与えられた 機能を処理するのに必要なデータ）から成るメッセージ通 信とすることにより, IP コアの標準化が容易になる。また, 使用者は個々の IP コアの処理手順を知る必要はなく, メッ セージを送るだけという統一した使用法で複数の IP コアを 使うことができる。

筆者らは現在，データ長に制限されず，且つIP コアの再 利用性と使用容易性を考慮した設計法の研究を行ってい る。その設計法を楕円曲線暗号アクセラレータに適用し, FPGA で試作し, 提案する設計法の有効性を検証した ${ }^{(10)}$ 。そ の設計法とは，基本となるモジュールは単体でも IP コアと して機能するが, 通常, 複数の同一基本モジュールをカス ケードに接続して IP コアは構成される。多種多様な IP コア の中から特定の IP コアを指定するメッセージとその処理に 必要なデータをパラメータとしてバスに送出すると指定さ れた IP コアがパラメータを取り込み処理結果を返す。その 際，IP コアはデータ長に合った必要なモジュール数，クロ ック周波数, クロック数および不必要な基本モジュールの スタンバイモードなどを IP コア内で判断し, 外部からの制 御を一切必要としない安全自立形の IP コアとして機能す る。これにより SoC で課題となっている IP コア間のインタ フェースの標準化, IP コアの再利用性と使用容易性, 最適 なクロック周波数とクロック数による効率的な処理および 消費電力の抑制などが期待できる。図 1 に試作した楕円曲 線暗号アクセラレータの構成図を示す。四則演算コアとそ れらを再利用してより高機能な IP コアを構成し, 平方剩余 コア (Compute EC Points), 棈円曲線上の点加算・点倍算コ ア $(\mathrm{EC} \mathrm{A} / \mathrm{D})$, 楕円スカラー倍算コア $(\mathrm{ECSM})$, 暗号化・復

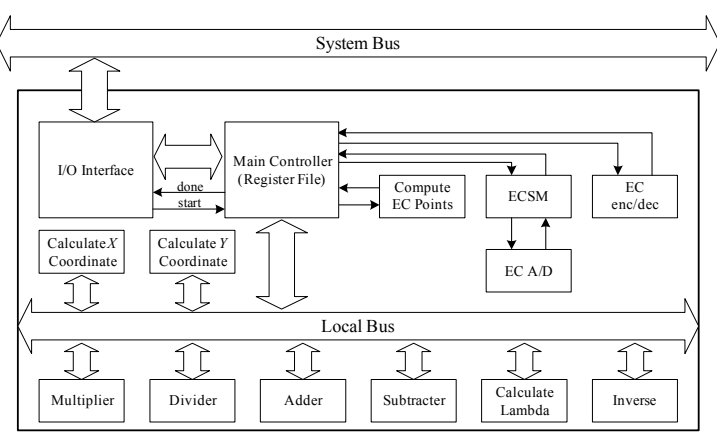

図 1 棈円曲線暗号アクセラレータの構成

Fig. 1. Structure of ECC Accelerator

号コア (EC enc/dec), X と Y 座標の算出コア (Calculate, X,Y coordinate）および逆元コア（Inverse）などのコアから成る。 図 1 の楕円曲線暗号アクセラレータは単純なカスケード接 続により，鍵の長さ（データ長）に制限されることのない モジュール化を実現したものである。類似研究中ではバス 幅 32 ビットで最も高速処理が期待できる結果が得られた。

IP コア間の通信フォーマットを図 2 に示す。簡単なため に, 1 ワードを 8 ビットで設計した。通常, メッセージはそ れぞれ 1 ワードの IP コア指定と, パラメータの長さを示す 精度情報（データ長）から成る（それぞれワード単位に拡 張可)。対象とする IP コアは多種多様であるが棈円曲線暗号 システムの試作に際して適用した四則演算器を例に挙げて 説明する。メッセージ部分の IP コア指定（図 2(a)）で，そ の上位 2 ビットは四則演算器のオペランドのタイプ用に用

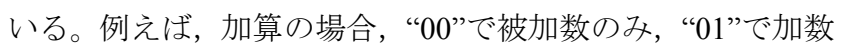
のみ, “10”で被加数と加数とする。従って, この場合 64 個 の IP コアまで対応できる。それ以上必要なら“11”として IP コアの指定を 1 ワード追加して拡張する。精度情報 (図 2(b)） は1 ワードの MSB を拡張用ビットとし, “0”で 0〜127 ワー ド (バイト) のデータを指定。それ以上の場合は MSB を“1” とすることにより 1 ワードの追加を意味し，16,383 ワード までデータ長を拡張することができる（それ以上も同様に ワード単位に精度情報を追加可能)。

バス上に図 2 のメッセージとパラメータを出力する場合 はメッセージの開始を示すオール“0”（1 ワード）と通信の 終了を意味するオール“1”（5 ワード）を付加する。全ての IP コアは 1 ワードのバスが全て“0”のメッセージ開始フレー ムを検出したら, 次の 1 ワードから IP コアの指定を判断し, 自分宛だったら続けて送られてくる精度情報に従って, パ ラメータを取り込む。自分宛でなかったら, 続いて送られ てくるデータを無視し，5 ワード分の連続した“1”を検出し て通信の終了を知る。パラメータ中に“1”が 4 ワード以上連 続するデータがある場合は, 連続した 4 ワードの“1”の次に は必ず 1 ワードの“0”を挿入し, 受信する場合はその“0”を取 り除く操作を行うことによって, 通信終了の誤判定を防ぐ （メッセージ開始を示す 1 ワードのオール 0 以降, データ中 にオール 0 が含まれていても, それが再度メッセージの開 始と誤判定されることはない)。 


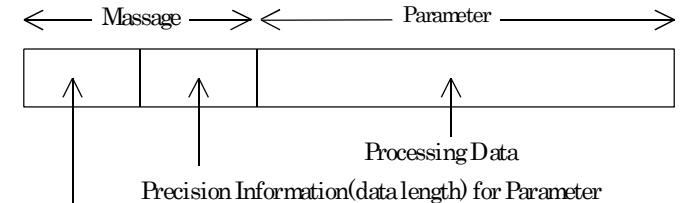

Appointment of IPcore

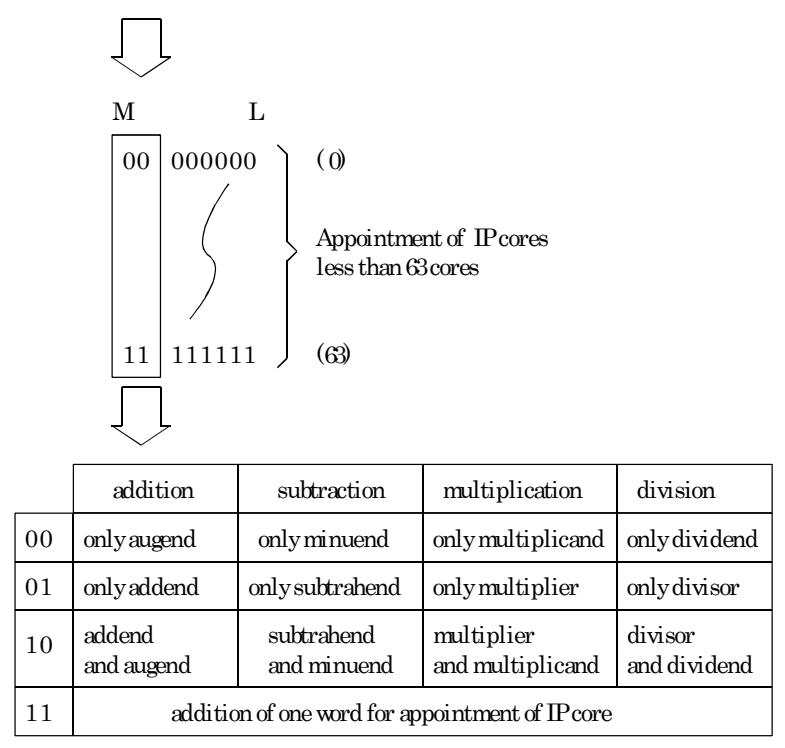

(a) An example of the appoint of IP core

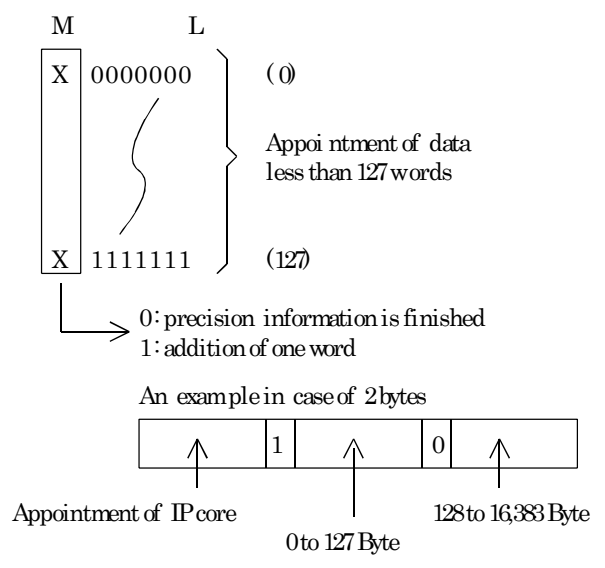

(b) Precision information(data length) for parameter

図 2 IP コア間の通信フォーマット

Fig. 2. A communication format between IP cores

IP コアの指定する相手のアドレスである論理アドレスを 集積時に決定した物理アドレスに変換する必要がある。そ のため, IP コアと ACU 間ではIPコアの論理アドレスと ACU の物理アドレスの変換が必要となる。ACU 間の通信フォー マットを図 3 に示す。送信データの IP コア指定には IP コア からの論理送信アドレスをその ACUのアドレスに送信アド レスとして付加し, 続けて, 送信する ACUのアドレスを送 信元アドレスとして付加して送信する（図 3(a)）。指定した IP コアで処理された結果は IP コア指定の送信元と送信先ア ドレスを逆にして，バスに送出される（図 3(b)）。

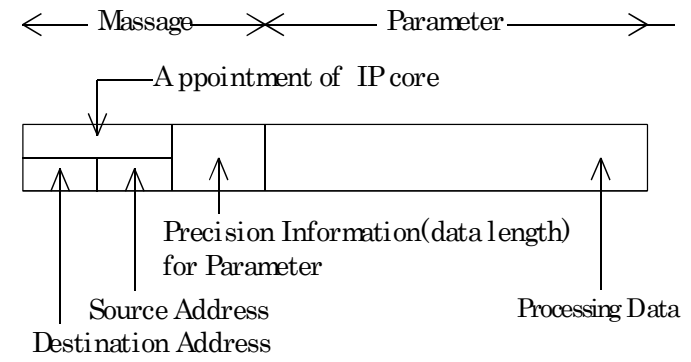

(a) Send data

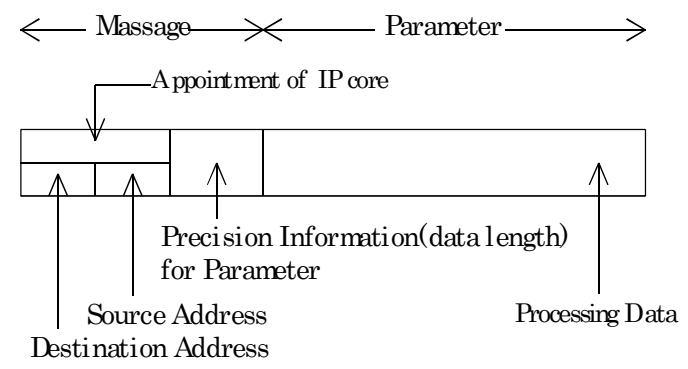

(b) Receive data after processed

図 $3 \mathrm{ACU}$ 間の通信フォーマット

Fig. 3. Send/receive data format between IP cores

\section{3. 通信制御機構の概要}

IP コアとバス間に提案する通信制御機構（Access Control Unit : ACU）を各 IP コアごとに配置し, 開発元の異なる各 IP コア間のインタフェースをとることでIP コアの再利用が 容易になり, 課題となっている各種 IP コアの標準化の問題 が解決できる。更に，チップ上でのネットワークを形成す るにあたり, 従来のバス形構成ではバス調停機構の問題が 伴うが，コンピュータネットワークで用いられているトー クン方式を ACUの連携に用いることでバスの使用権を制御 する。これにより全 IP コアのバスの使用要求を集中的に調 停する従来のようなバスアービタを構成するといったバス 調停機構が不要になる。

ACU の特徵として, どの IP コアに対してもすべて全く同 じアーキテクチャであり，接続する IP コアに合わせた設定 をする必要は無く単純に IP コアと接続するだけで IP コア間 の通信を行うことができる。さらにゲート数も $5 \mathrm{~K}$ ゲートほ どなので数千万ゲート規模の SoC のような超高集積回路内 というような現状を考えると問題とならない規模で実現で きる。

ACU モジュールの概要を図 4, シミュレーションを図 5, そして, IP コアの論理アドレスを ACU の物理アドレスに変 換するテーブルに関しては, IP コアが 4 つの簡単な例で表 1 に示し，以下に各機構の概要を述べる。

トークン制御機構（図 5(a)）はトークン通知線, トークン 終了検知線, IP コアの通信要求の有無によってトークンを 保持するか，パス寸るかを管理および初期トークンを発生 する機構である。集積時に任意に指定したひとつの ACU で 一定時間（時間は任意に指定できる）経過したら初期トー 


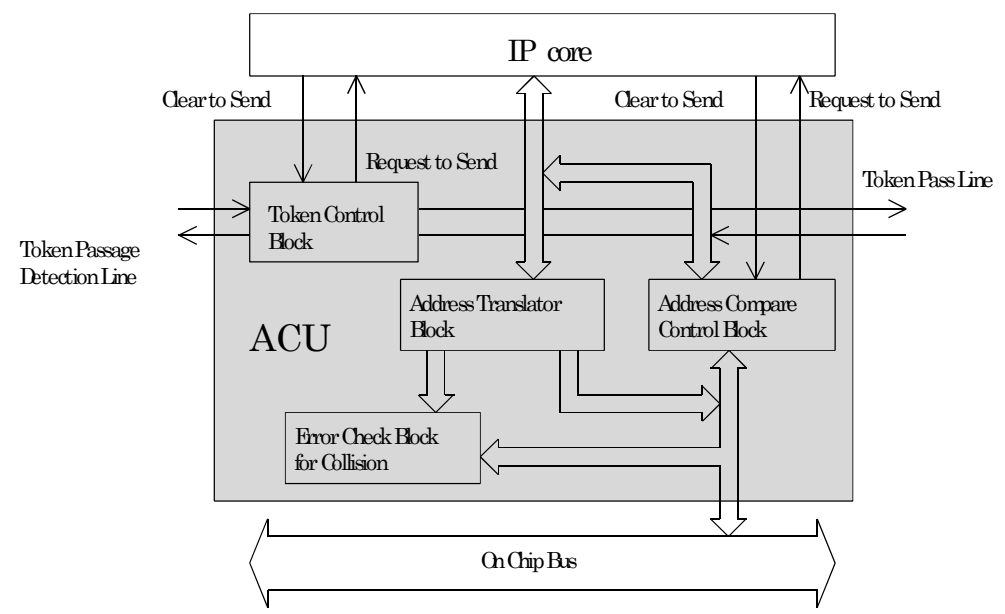

図 4 ACU モジュールの概要

Fig. 4. Online of the ACU Module

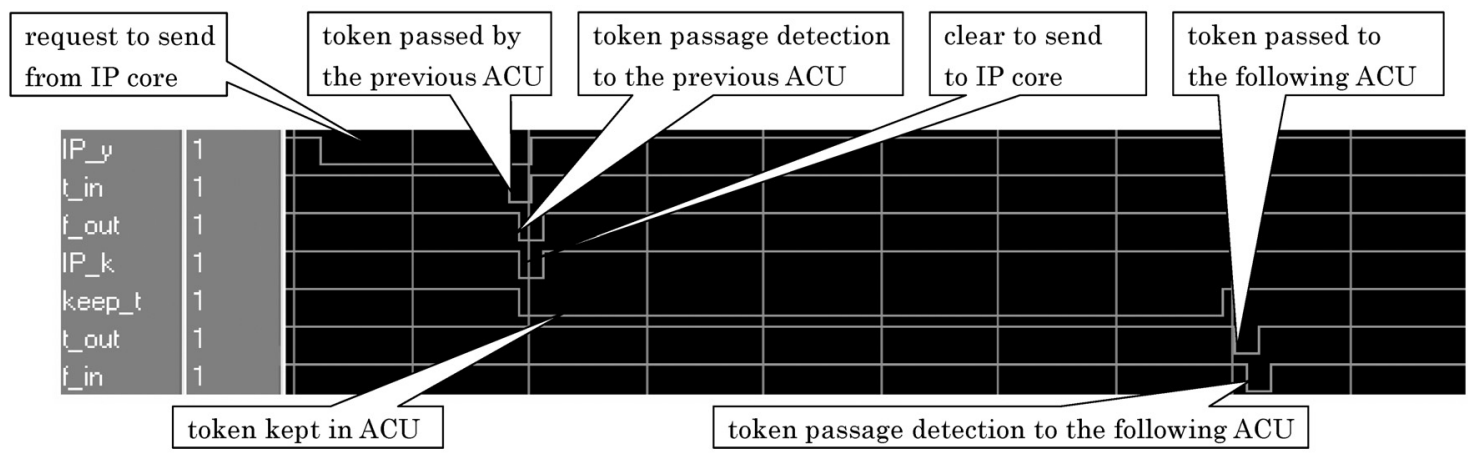

(a) Token control block

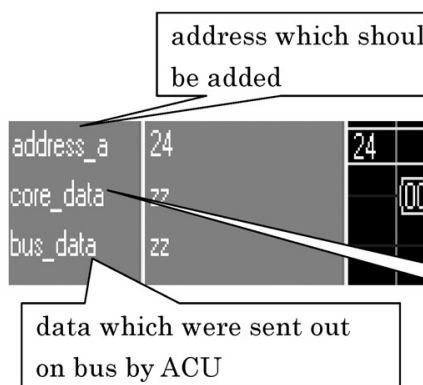

\begin{tabular}{|l|l|}
\hline logical address of IP core & physical address of ACU \\
\hline
\end{tabular}

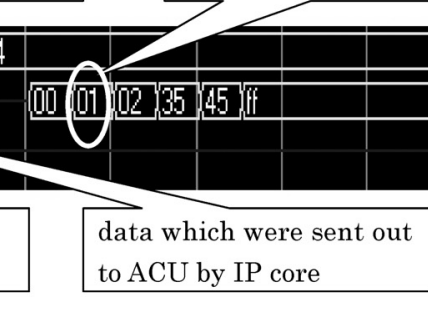

(b) Address translator block

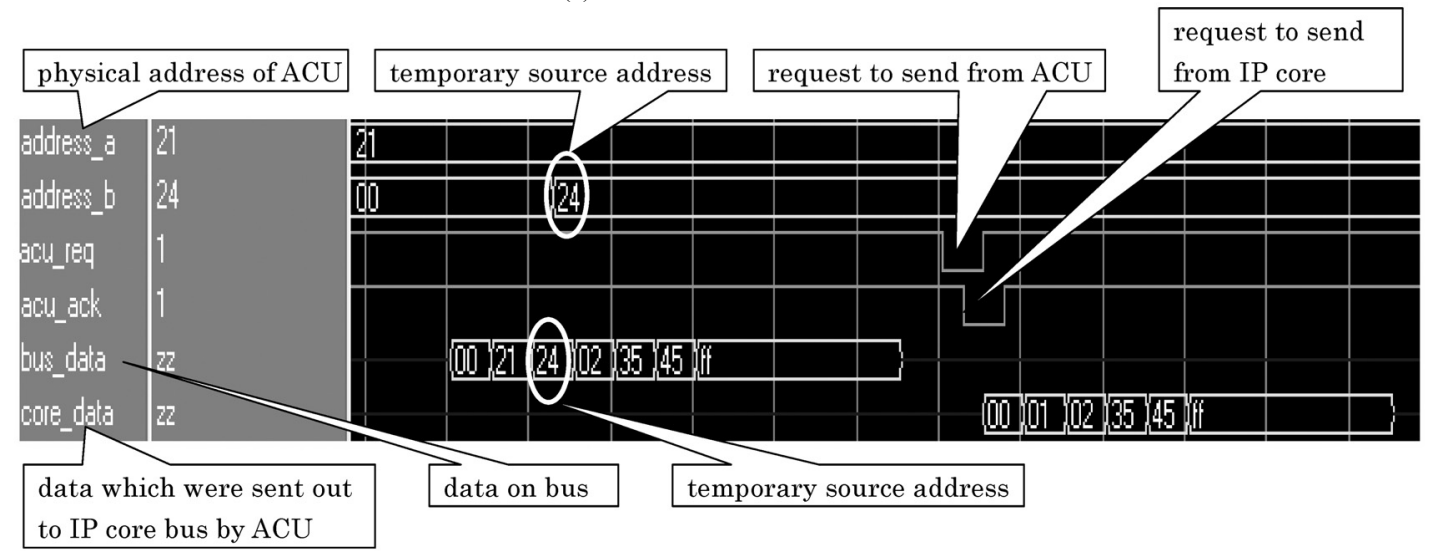

(c) Address compare control block

困 5 シミュレーション結果

Fig. 5. Result of simuration 


\section{表 1 アドレステーブルの例}

Table 1. Example of address table

\begin{tabular}{|l|l|l|l|l|}
\hline IP core(logical address) & 01 & 02 & 03 & 04 \\
\hline ACU (physical address) & 21 & 22 & 23 & 24 \\
\hline
\end{tabular}

クンを出力する。IP コアからの通信要求があり（IP_y=0）, トークン通知線からトークンが入力されたとき $(\mathrm{t}$ _in=0), IP コアへの通信許可（IP_k=0）を出力し，トークンを保持する (keep_t $=0)$ 。保持したトークンはデータ通信が終了したら次 の $\mathrm{ACU}$ ヘトークンをパスする（t_out=0）。IP コアからの通 信要求がなければ次の ACU ヘトークンをパスする。トーク ンを確実にパスするため, トークン通知線とトークン終了 検知線はハンドシェイク方式を採用している。これにより トークン通知線がアクティブになったら直前の ACU のトー クン終了検知線をアクティブにし (f_out $=0)$, トークン通知 を終了する。このトークンに相当するアクティブ信号をル ープ状にパスしていくことでバスの使用権を決定する。

また，なんらかのエラーでトークンが消滅してしまった 場合，任意に指定した機構が一定時間経過することで新た なトークンを出力する（初期トークンの出力と同様な状 態)。

アドレス変換機構（図 5(b)）は IP コアからデータ （core_data）を送信する場合, 送信先の IP コアの論理アドレ スを $\mathrm{ACU}$ の物理アドレスに変換し $(01 \rightarrow 21)$, 送信元の $\mathrm{ACU}$ アドレスを付加して（address_a=24），オンチップバスにデ ータを送出する（bus_data）。送信後，指定した IP コアから その IP コアの ACU に返送された処理結果は, アドレス判 別機構で一時保存していた送信元アドレスを送信先アドレ スとし，元々の送信先アドレスを送信元アドレスとして， オンチップバスにデータを送出し, 送信元の ACUに返送す る。

アドレス判別機構（図 5(C)） はオンチップバスから送ら れてくるデータが自宛であるかを判別する。自宛でなけれ ば続けて送られてくるアドレス以降のデータを無視する。 自宛であれば, 続けて送られてくるパラメータを取り込み, IP コアへ通信要求を出力する (acu_req=0)。IP コアから通 信許可（acu_ack=0）を得たら，送信元アドレスを取り除い て IP コアヘデータを送出する (core_data)。このとき取り除 いた送信元アドレスは，IP コアで処理されたデータを送信 元の IP アアへ返送するために一時保存される (address_b=24)。

エラー判別機構はオンチップバスヘデータを出力すると 同時に取り込み，オンチップバスへ出力する前のデータと 比較する。出力後のデータが出力前のデータと違っていた らオンチップバス上でデータが衝突していると判断する。 これは本来 1 つであるべきトークンが誤動作で 2 つ以上存 在してしまった結果, 生じたことであるので, エラー信号 を出力して (該当する IP コアに対しては精度情報を“0”とし て再送要求を行なう）ACU を初期化する（トークンを非ア クティブにし，トークンが全くない初期状態にする）。

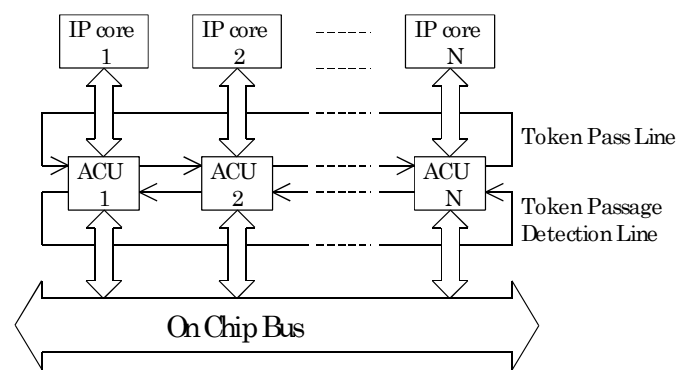

図 6 IP コアの接続概要

Fig. 6. Connection outline of the IP cores

\section{4. 提案する通信制御機構}

バスの使用権はトークン方式によって決定する。この方 式を用いることで, バス方式で問題となるバス調停機構を 必要とすることなく, 単純な構成でバスの使用権を制御す ることができる。

提案する通信機構の通信例として, IP コア 2 から IP コア $\mathrm{N}$ 一通信を行う場合の手順を図 6 で説明する。IP コア 2 か ら IP コア Nへのデータは, IP コア 2 に接続されている ACU2 に通信要求信号があり, トークンを取得することで ACU2 は IP コア 2 に通信許可信号を出力する。許可を得た IP コア 2 は接続されている ACU2 ヘデータを送出する。ACU2 は送 信先アドレス（IP コア $\mathrm{N}$ のアドレス）をオンチップバス側 アドレス（ACUNのアドレス）に変換し, 続けて ACU2 の 送信元アドレスを付加したデータをバス上に送出する。各 ACU はメッセージの開始を検知すると, 一斉にメッセージ を取り込み，送信先アドレスと自分のアドレスを比較し， 一致（この場合 IP コア N）したものだけが続けて送られて くるパラメータを取り込み, 接続されている IP コアへ通信 要求を出力する。IP コア $\mathrm{N}$ から通信許可が得られたら, IP コア $\mathrm{N}$ に接続されている ACU N は送信元アドレス (IP コア 2 のアドレス）を ACU N に一時保存し，それを取り除いた データを IP コア $\mathrm{N}$ へ送出する。

IP コア N で処理されたデータは, 接続されている ACU N へ返送され，一時保存していた送信元アドレス（IP コア 2 のアドレス）を処理後のデータの送信先アドレスとし, バ ス上に送出する。ACU2 の送信時と同様に, すべての ACU がアドレス判別を行い，アドレスが一致した IP コア 2 の ACU2 だけが続けて送られてくる IP コア N の処理結果を受 信し, IP コア 2 に送出する。通信終了後, トークンはトー クン通知線によって次の ACU である ACU3 ヘパスされる。 これによって次は IP コア 3 がバスの使用権を得る。

IP コア Nに接続されている ACU Nからトークンがパスさ れた場合は IP コア 1 に接続されている ACU1 ヘパスされる というようにトークン通知線をループ状に構成してトーク ンを循環させる。

\section{FPGA での試作特性}

提案する IP コア間の通信方式は多種多様な IP コアの機能 
表 2 試作と評価結果

Table 2. Experiment and evaluation result

\begin{tabular}{|c|c|c|c|c|c|c|}
\hline & $\begin{array}{l}\text { Multiplication } \\
\text { (8bit) }\end{array}$ & $\begin{array}{c}\text { Comparison } \\
\text { (8bit) }\end{array}$ & $\begin{array}{l}\text { Addition } \\
\text { (8bit) }\end{array}$ & $\begin{array}{c}\text { Subtraction } \\
\text { (8bit) }\end{array}$ & $\mathrm{ACU}$ & $\begin{array}{l}\text { Inspection } \\
\text { circuit }\end{array}$ \\
\hline Number of input signals & 4 & 4 & 4 & 4 & 23 & 2 \\
\hline Number of output signals & 2 & 2 & 2 & 2 & 4 & 0 \\
\hline Number of I/O signals & 8 & 8 & 8 & 8 & 17 & 0 \\
\hline Gate count & 1,774 & 1,753 & 1,647 & 1,650 & 4974 & 26,620 \\
\hline Maximum frequency(MHz) & 95.216 & 96.681 & 96.844 & 96.815 & 247.173 & 69.434 \\
\hline
\end{tabular}

に依存しない全く同じアーキテクチャで実現できる。提案 する通信機構の実証のため IP コアとしては簡単な 8 ビット の乗算器, 加算器, 減算器および比較器を用意し, Xilinx 社 のVertex-4 に組み込んで試作・実験を行った。1 ワードを 8 ビット, IP コア間の指定数が $0 \sim 63$ とした場合の評価結果 を表 2 に示す。システム全体の動作速度はそれぞれの IP コ アの処理時間よるもので, ACU 自体は小規模で, 高速に動 作可能である。

\section{6. 比較}

複数の IP コアをひとつのチップに集積するような SoC で は IP コア間の通信を行う NoC の構成が不可欠となる。オン チップバスに関する規格として，システムバスとペリフェ ラルバスで構成し，複数のバスマスタから成る ARM 社の AMBA 仕様が普及してきている(11)。また, SONICS 社の提 供する OCP（Open Core Protocol）は IP コア間の通信を行う ためのプロトコルが規定されており, IP コアやバスが OCP に準拠していれば IP コアの再設計が不要になる(12)(13)。その 他, STMicroelectronics 社の STNoC, ALTERA 社の Atlantic インターフェース ${ }^{(14)}$ など独自の通信方式が開発されてい る。

既存の類似方式として，現在製品化されている STMicroelectronics 社の STNoC と SONICS 社の SonicsMX が あり，提案する方式との比較検討を行った。STNoC は提案 する方式と同様に全 IP コアが，時計回りと反時計回りのバ スでループ状に接続され, 更に, 対角線上に存在する IP コ アブロックと接続される。従って, 各 IP コアには左, 右お よび対角線上の 3 つの接続線があり, パケット通信機構の ルータを備えた NoCである(13)。SonicsMX は OCP に準拠し たプロトコルである標準インタフェースの OCP ソケットを 介して IP コアがシステムインターコネクトに接続されるも のである。筆者らが提案する方式は以上の研究と比較して, 単純な一系統の並列バスで，インタフェースプロトコルは メッセージとパラメータによる通信に限定したことにあ る。そのためインタフェースの ACU は特定の IP コアに依 存しない全く同一のアーキテクチャで，インタフェースの 標準化が容易であり，表 2 で示すように約 $5 \mathrm{k}$ ゲートと小規 模で，高速動作が実現できることを特徵とするものである。 提案する方式によりどの程度複雑な IP コア間のデータ通信 が可能であるかを検証するため, 筆者らは 2 章で述べたよ うに楕円曲線暗号アクセラレータに適用し, 提案する方式
が十分に有効であることを検証した。

\section{7. まとめ}

IP コアのハードウェア設計法によるインタフェースの標 準化の問題を解決する一手法を提案し, それを実現するた めのインタフェース機構の設計と検証を FPGA で行った。IP コアとバス間のインタフェースとなる通信制御機構 (ACU) は多種多様な機能をもった IP コアに対して, 全く同じアー キテクチャであり，約 $5 \mathrm{k}$ ゲートの規模で実現できる。この 手法を用いることにより供給元の異なる IP コア間のインタ フェースの標準化はメッセージとパラメータの通信だけと なり, 単純なメッセージ通信によって IP コア間の通信を行 うことができる。これにより，IP コアはソフトウェアのよ うに柔軟性のあるモジュールとして考えることができるた め, 新たに IP コアを付加しようとした場合でも容易に対応 できる。提案するハードウェア設計法により使用者は内部 仕様を知る必要がなく, 多くの IP コアを容易に集積化およ び使用することが可能となる。

(平成 18 年 8 月 17 日受付, 平成 19 年 1 月 4 日再受付)

\section{文献}

(1) L. Benini and G. D. Micheli : "Networks on Chips : A New SoC Paradaim", IEEE, Computer, pp.70-78 (2002-1)

(2) P. P. Pande, C. Grecu, M. Jones, A. Ivanov, and R. Saleh : "Performance Evaluation and Design Trade-offs for Network-on Chip Interconnect Architectures", IEEE Trans. on Computers, pp.1025-1040 (2005-8)

(3) H. Matsutani, M. Koibuchi, and H. Amano : "A Virtual- channel Free Routing Strategy for On-chip Torus Networks", Vol.47, No.SIG12, pp.12-24 (2006) (in Japanese) 松谷宏紀・鯉㴊道紘・天野英晴:「オンチップトーラス網における仮 想チャネルフリールーティング」, 情処論, コンピューティングシス テム, 47, SIG12, pp.12-24 (2006)

(4) 唐木信雄：「非同期回路設計のす寸め」, Design Wave, 7, pp.64-69 (2005-7)

（5） R. Goering : 「次世代システム LSI の性能限界オンチップ・バスが鍵 を握る」, EE TIMES Japan, No.3, pp.32-33 (2005-9)

(6) M. W. Heath, W. P. Burleson, and 1. G. Harris : "Synchro-Tokens: A Deterministic GALS Methodology for Chip-Level Debug and Test", IEEE Trans. on Computers, Vol.54, No.12, pp.1532-1546 (2005-12)

(7) K. Anjo, M. Koibuchi, Y. Yamada, A. Jouraku, and H. Amano : "Evaluation of Local Labeling Scheme on Network-on-Chip", IEICE Trans, D-I, Vol.J88-D-I, No.6, pp.1076-1090 (2005) (in Japanese) 安生健一郎・鯉㴊道紘・山田 裕・上楽明也・天野英晴: 「ネットワ ークオンチップにおけるローカルラベリングカ式の評価」, 信学論, D-I, Vol.J88-D-I, No.6, pp.1076-1090 (2005) 
(8) K. Furuya, T. Nakamura, N. Fuyutsume, and H.Kasahara : "Design and Collaboration for IP Cores by an Object-oriented Technology", Kansai section Joint Convention of IEE, G10-15 (2003) (in Japanese)

古屋憲吾・中村次男・冬爪成人・笠原 宏 :「オブジェクト指向技術 を導入した IP コアの設計とその連携方式」, 電気関係学会関西支部 連大 G10-15 (2003)

(9) M. Hayakawa, T. Nakamura, M. Sato, H. Hatakenaka, N. Fuyutsume, H. Kasahara, and T. Tanaka : "A Communication Technique between IP cores in SoC", Proc. IEEJ-EISConf., GS2-2, pp.746-750 (2005)

早川雅文・ 中村次男 - 佐藤正幸 - 畠中浩行 - 冬爪成人 - 笠原 宏 田中照夫：「SoC 内 IP コア間の通信方式」, 平 17 電学電子・情報・ システム部門大, GS2-2, pp.764-750 (2005) (in Japanese)

(10) M. Sato, T. Nakamura, H. Hatakenaka, N. Fuyutsume, H. Kasahara, and T. Tanaka : "A Design Method of Self-Supporting Scalable IP Core and Application to Elliptic Curve Cryptosystem Design”, Vol.48, No.2, pp.868-879 (2007) (in Japanese)

佐藤正幸・中村次男・畠中浩行・冬爪成人・笠原 宏・田中照夫 :「完 全自立形スケーラブル IP コアの設計法と楕円曲線暗号処理システ ムへの適用例」, 情処論, 48, 2, pp.868-879 (2007)

(11) http:www.jp.arm.com/kk/amba_index.html

(12) KAWASAKI MICROELECTRONICS, INC. "SONICS smart interconnect IP News Release" (2004-4)

(13) http://techno.nikkeibp.co.jp

(14) http://altera.co.jp/products/ip/altera/t-alt-atlantic.html

早 川 雅 文 (正員) 1982 年 6 月 28 日生。 2005 年 3 月東

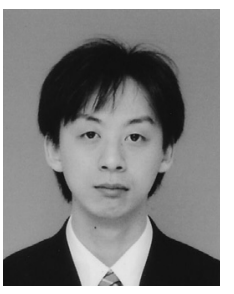
京電機大学工学部電気工学科卒業。2007 年 3 月東京電機大学大学院修士修了。

中 村 次 男 (正員) 1948 年 6 月 19 日生。1971 年 3 月東

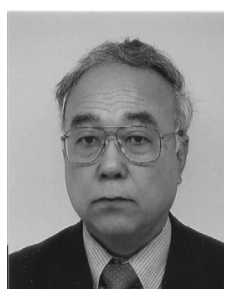
京電機大学工学部電気工学科卒業。同年, 4 月 日本電気精器 (株) 入社。1990 年 3 月東京電機 大学大学院修士修了。現在, 東京電機大学大学 院情報環境研究科客員教授。博士 (工学)。デ イジタル演算機器, 高速暗号, 集積回路の盗用 防止機構，オブジェクト指向ハードウェア設計 法に関する研究に従事。著書「ディジタル回路 の基礎」(日本理工出版会)，「ディジタル回路設計法-ワンチップ化 の実例集-」(日本理工出版会)，「ディジタル回路入門」（日本理工 出版会), 「電子回路(2)ディジタル編」(コロナ社), 「電気・電子なぜなぜおもしろ読本」(山海堂)。IEEE 会員。

冬爪成人（正員） 1970 年 10 月 9 日生。1995 年 3 月東

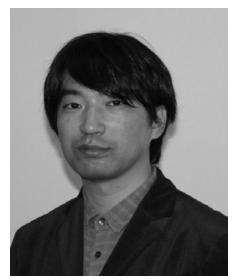
京電機大学工学部電気工学科卒業。2000 年同大 学大学院博士課程修了。同大学工学部電気工学 科助手, 同大学情報環境学部情報環境工学科助 手を経て, 現在, 同学部同学科講師。博士（工 学)。コンピュータネットワークに関する研究 に従事。電子情報通信学会会員。

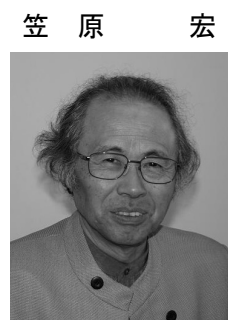

（正員） 1940 年 4 月 12 日生。1970 年 3 月東 京電機大学大学院博士課程満期退学。同大学助 手, 講師, 助教授を経て工学部電気工学科教授。 現在, 情報環境学部情報環境工学科教授。工学 博士。パワーエレクトロニクス, 計算機システ ム, 制御用分散処理システム, オブジェクト指 向システム設計法, インタラクティブにとらえ た脈診情報処理方式, 高速暗号化に関する研究 に従事。情報処理学会, 電子情報通信学会, IEEE, ACM 各会員。

田 中 照夫

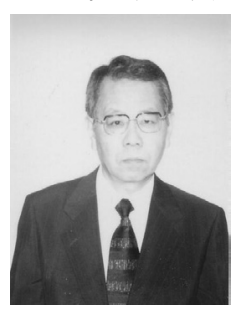

（正員） 1943 年 9 月 19 日生。1972 年 3 月東 京電機大学大学院工学研究科博士課程満期退 学。主としてパワーエレクトロニクスに関する 研究に従事。1 969 年同大学助手, 専任講師, 助 教授を経て, 現在, 同大学工学部電気工学科教 授。IEEE 会員。 